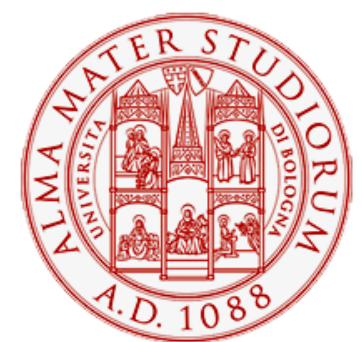

Alma Mater Studiorum - Università di Bologna DEPARTMENT OF ECONOMICS

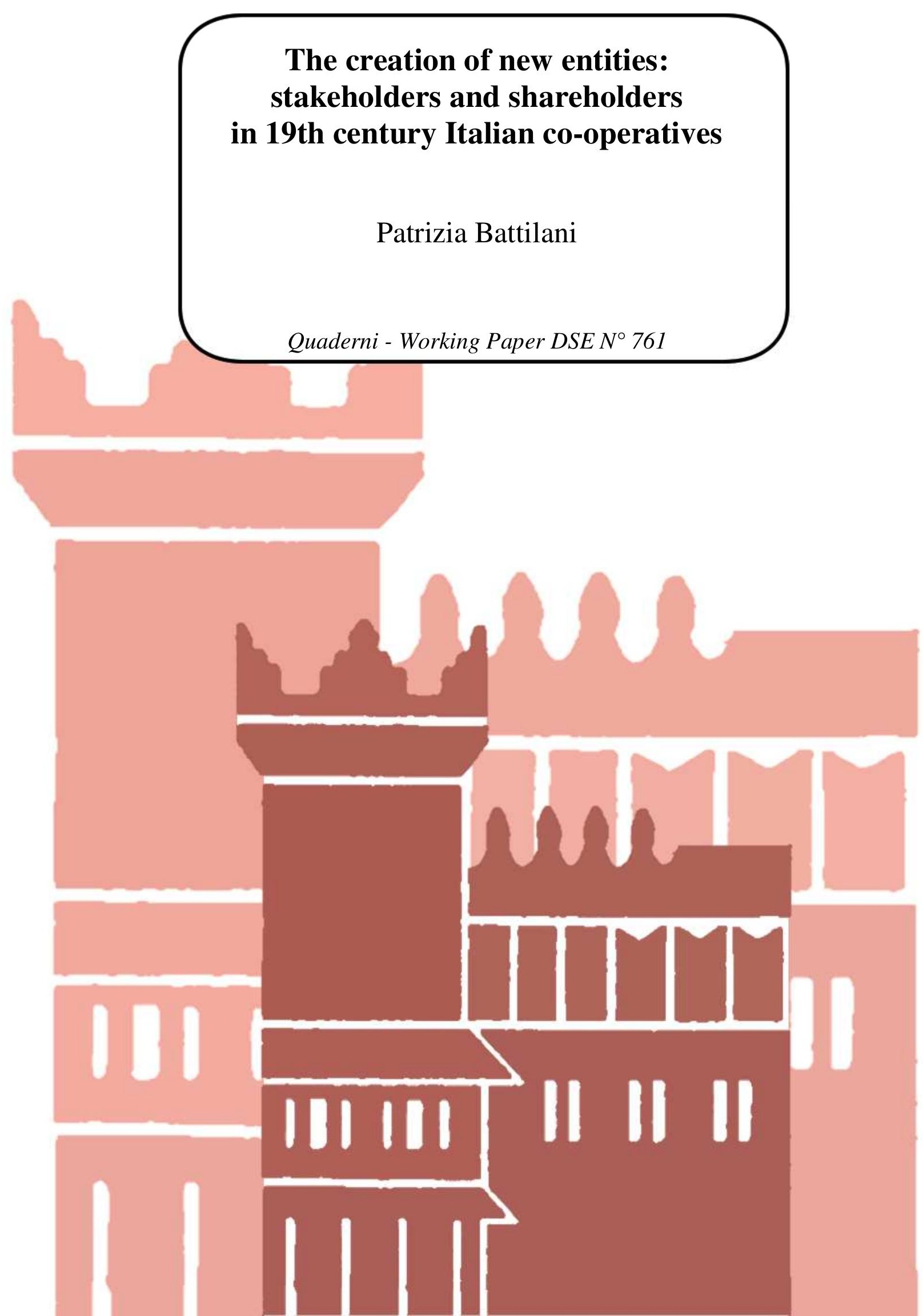




\title{
The creation of new entities: stakeholders and shareholders in 19th century Italian co-operatives
}

\author{
Patrizia Battilani, Economics department, University of Bologna
}

\begin{abstract}
The numerous studies made of the persistence of the co-operative movement during the course of the 20th century, have often distinguished between economic efficiency and the ethical values (or ideologies) in questioni, as if the two were separate phenomena moving in parallel directions.

However, over the past fifteen years at least two approaches have led to an interweaving of the cultural aspects of co-operation with the question of economic efficiency: the Putnam's concept of social capital and the property rights model based on the work of Henry Hansmann.

In associating myself with an approach, where efficiency is linked with "culture", I wish to examine the cultural components of the Italian cooperative movement which emerged from three different socio-cultural traditions: liberalism, catholicism and socialism. Despite their differences, all three seem to share what we refer to here as the "ideal of community happiness", that is the ideal of a collaboration among citizens for the improvement of the standard of living of the whole community. In this paper we will measure the popularity of this culture in the various Italian regions by per capita welfare expenditure in 1880 and 1900. At that time everything spent for helping people in need was given by friendly societies, catholic charities and local councils and nothing came from the central state. Therefore only the spreading of non-profit societies and a proactive attitude by local councils could generate high per capita welfare expenditure. Indeed, such indicator would seem to be closely linked to co-operative expansion during the second half of the 19th century, and would thus appear to provide an explanation for the non-homogeneous 212 geographical distribution of Italian co-operatives. The main conclusion of this essay is that in the early stages the link with the political and cultural movements was crucial not only for the emergence but above all for the viability of cooperative enterprises by reducing the costs associated with collective decision making.
\end{abstract}

Keywords: cooperatives, community happiness, Italy, XIX century

Jel classification: N83 


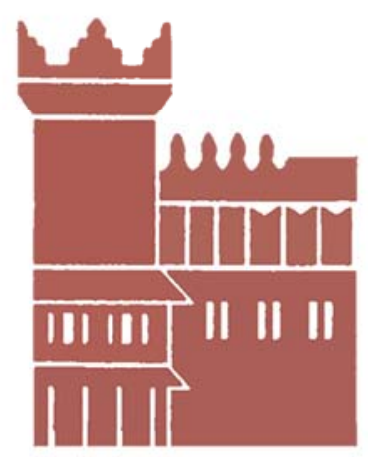

Alma Mater Studiorum - Università di Bologna DEPARTMENT OF ECONOMICS

Strada Maggiore 45

40125 Bologna - Italy

Tel. +39051 2092604

Fax +390512092664

http://www.dse.unibo.it 